scheiden sie sich jedoch morphologisch und auch durch ihre Lagerung so stark, daß eine Identität ausgeschlossen sein dürfte. Mit den kleindimensionalen Neurosekretgranula besteht eine gewisse Ähnlichkeit. Die Granula sind aber, soweit wir uns in der Literatur über ihr Vorkommen in den einzelnen Hirnteilen orientieren konnten, im Ammonshorn bisher nicht beschrieben worden. Außerdem haben wir in Präparaten des Ammonshorns normaler Kaninchen und des Großhirns normaler Hühnerembryonen bisher keine Gebilde gefunden, wie sie im infizierten Material vorhanden waren.

Es ist nicht ausgeschlossen, daß die beschriebenen kugelförmigen Gebilde, die wir im Gehirn experimentell infizierter Kaninchen und Hühnerembryonen nachweisen konnten, zum Tollwutvirus in Beziehung stehen. Hierfür sprechen ihre Größe von $30-40$ $\mathrm{m} \mu$, die nach unseren Versuchen für das infektiöse Tollwutagens zutreffen würde, und ihre morphologische Ähnlichkeit mit manchen Virusarten, ferner die Gleichförmigkeit ihrer Struktur und ihr Auftreten in dichten Herdchen. Ob es sich um TollwutvirusKörperchen selbst, ihre unreifen Formen oder unter Viruseinwirkung entstandene Reaktionsprodukte handeln könnte, wäre später zu untersuchen, wenn die Beziehung dieser Gebilde zum Tollwutvirus eindeutig feststeht. Die Untersuchungen zur Klärung dieser Frage sind im Gange.

Herm Professor Dr. Bargmann, Kiel, und besonders Herrn Dr. Vogell, Marburg, danke ich für wertvolle Hinweise in der Deutung einiger Hirnstrukturen im elektronenmikroskopischen Bild.

\title{
Cytologische Studien über die Vermehrung des ME-Virus in L-Zellen
}

\author{
Lokalisierung der RNS- und Virusprotein-Synthese mit autoradiographischen \\ und fluoreszenzoptischen Methoden \\ Von Helga Hausen \\ Aus den Max-Planck-Instituten für Virusforschung (Abt. SchäfER) und \\ Biologie (Abt. Beermann), Tübingen \\ (Z. Naturforschg. 17 b, 158-160 [1962] ; eingegangen am 24. November 1961)
}

\begin{abstract}
Nichtinfizierte L-Zellen bauen ${ }^{3} \mathrm{H}$-Uridin bei kurzen Markierungszeiten fast ausschließlich in die RNS des Zellkerns, besonders in die des Nucleolus ein. In ME-infizierten Zellen wird die RNS. Synthese im Kern ab 2 Stdn. p. i. fortschreitend gehemmt; es beginnt darauf ein starker Einbau von ${ }^{3} \mathrm{H}$-Uridin in die RNS des Cytoplasmas. Zu annähernd gleicher Zeit läßt sich mit fluoreszierendem Antikörper Virusprotein im Cytoplasma nachweisen.
\end{abstract}

Das zur Columbia S.K.-Gruppe gehörende MEVirus wurde kürzlich aus infizierten Mäusegehirnen in kristallisierter Form isoliert und näher charakterisiert ${ }^{1}$. Nach diesen Untersuchungen ist es ein polyederartiges Partikel mit einem Durchmesser von $24 \mathrm{~m} \mu$, das aus RNS und Protein besteht; die Proteinhülle setzt sich aus Untereinheiten zusammen, die einen Durchmesser von etwa $5 \mathrm{~m} \mu$ haben. Die Vermehrung dieses Virus wurde in L-Zellen verfolgt ${ }^{2-4}$. Hier läßt sich die Bildung von infektiöser Virus-RNS bereits 2 Stdn. post infectionem (p.i.) feststellen; wahrscheinlich beginnt etwa zur gleichen Zeit auch die Synthese des Virusproteins. Infektiöse Partikel treten dagegen erst 3 Stdn. p. i. in nachweisbarer Menge auf. Die Frage war, an welchen Orten

\footnotetext{
1 P. Hausen u. W. Schäfer, Z. Naturforschg. 17 b. 15 [1962].

2 C. Henry u. R. M. Franklin, Virology 9, 84 [1959].

3 P Hausen u. W. Schäfer, Z. Naturforschg. 16 b, 72 [1961].
}

innerhalb der Wirtszelle die einzelnen Komponenten des Virus produziert werden. Um Aufschluß hierüber zu gewinnen, wurde die RNS-Synthese mit Hilfe einer autoradiographischen Methode, die Bildung von virusspezifischem Protein unter Verwendung von fluoreszierendem Antikörper verfolgt.

\section{Material und Methoden}

Die für die Untersuchung verwendeten L-Zellen wurden im Medium nach Charity Waymouth $(\mathrm{CW})^{5}$ auf Glasobjektträgern gezüchtet und mit etwa 100 plaquebildenden Einheiten (PBE)/Zelle infiziert. Als Impfmaterial dienten Extrakte aus ME-infizierten Mäusegehirnen, die durch Schütteln mit Frigen ${ }^{3}$ gewonnen wurden. Das Virus war darin in NaCl-Phosphatpuffer

\footnotetext{
${ }^{4}$ P. Hausen, Dissertation, Tübingen 1961.

5 C. W
} 

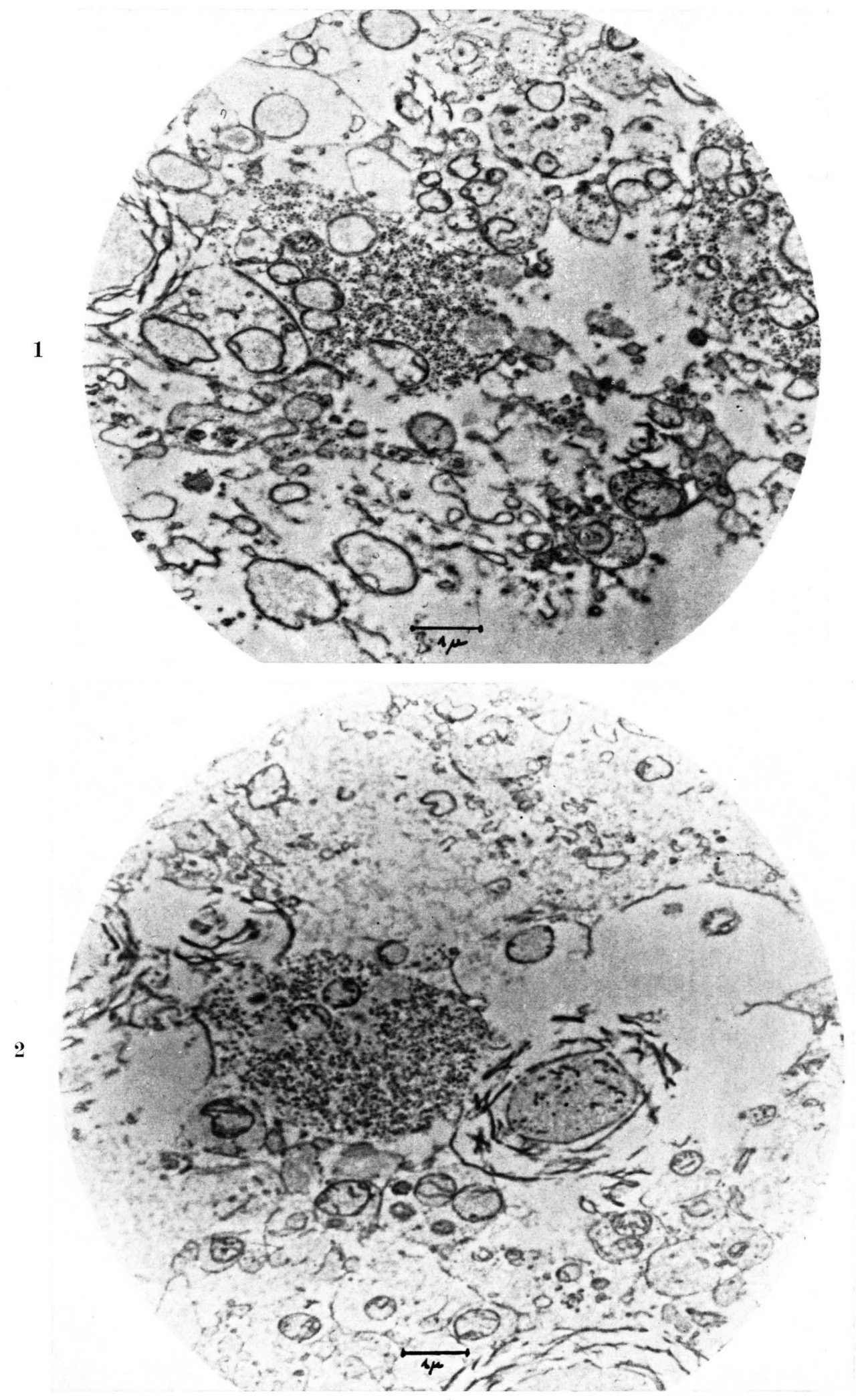

Abb. 1 und 2. Schnitte aus dem Ammonshorn vom mit Virus fixe infizierten Kaninchen. a) Übersichtsaufnahmen. Fixierung mit $\mathrm{KMnO}_{4}$. Vergrößerung 10000 -fach. 


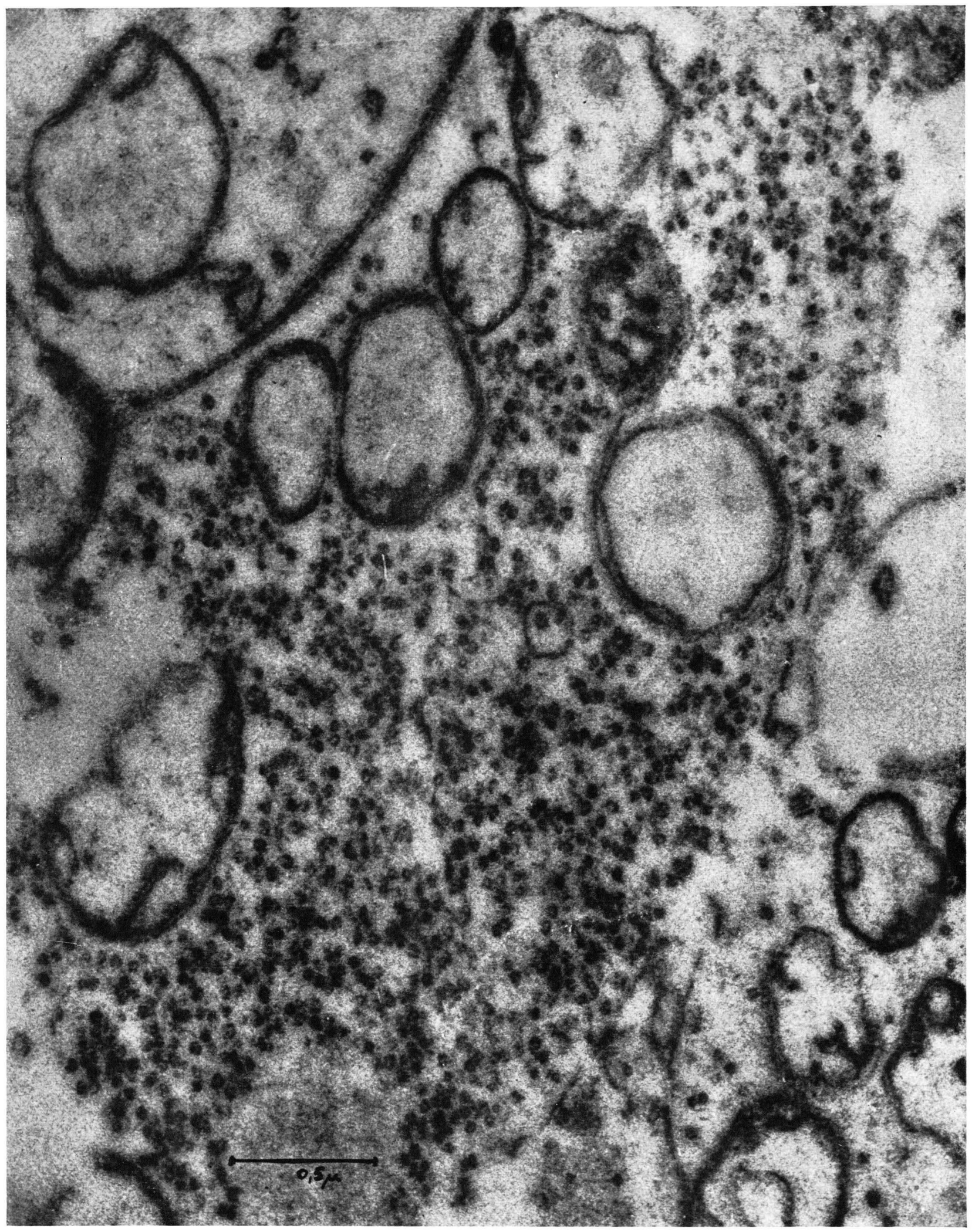

Abb. 3. Ausschnitt aus der Abb. 1. Vergrößerung 50 000-fach. 


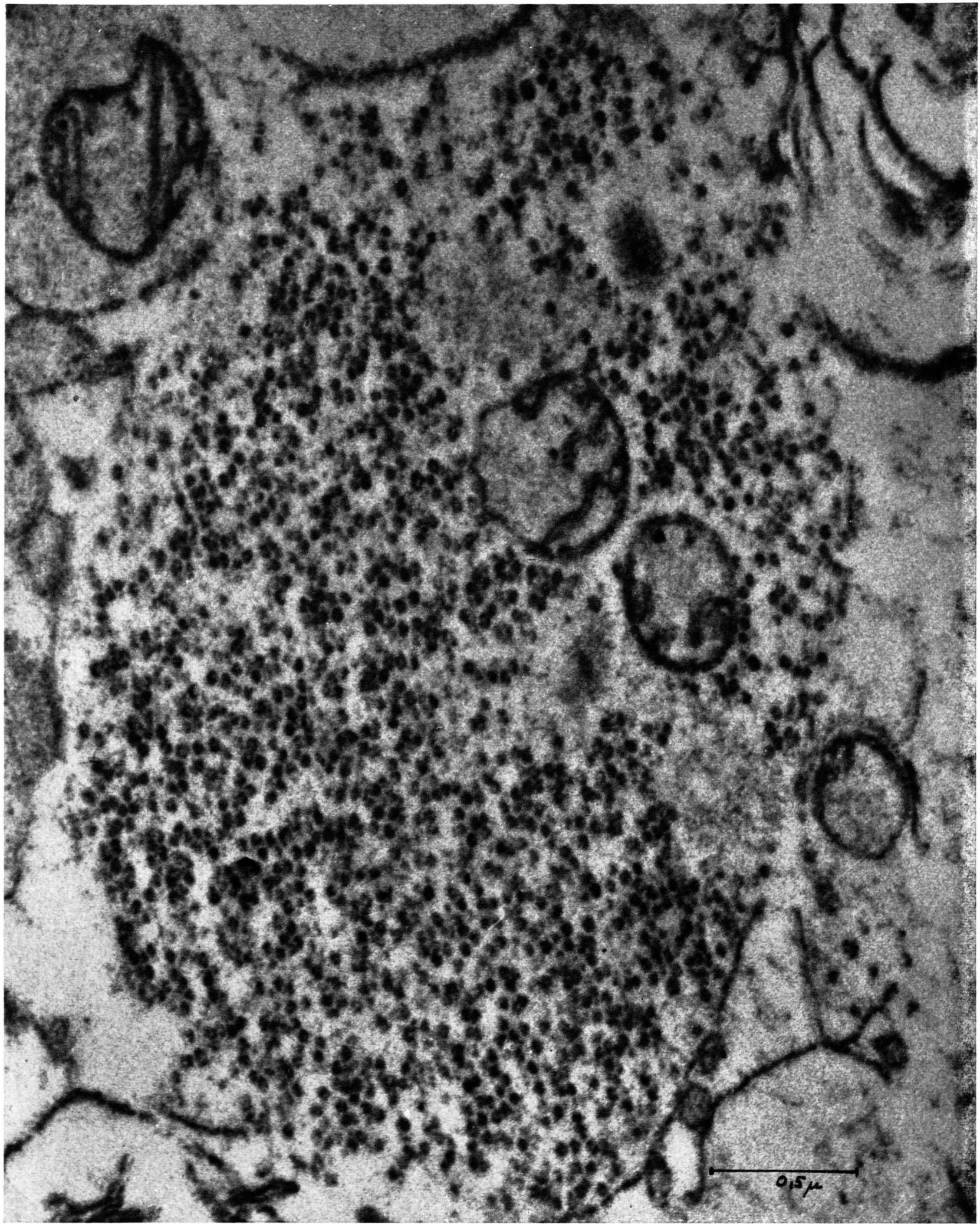

Abb. 4. Ausschnitt aus der Abb. 2. Vergrößerung 50 000-fach. 

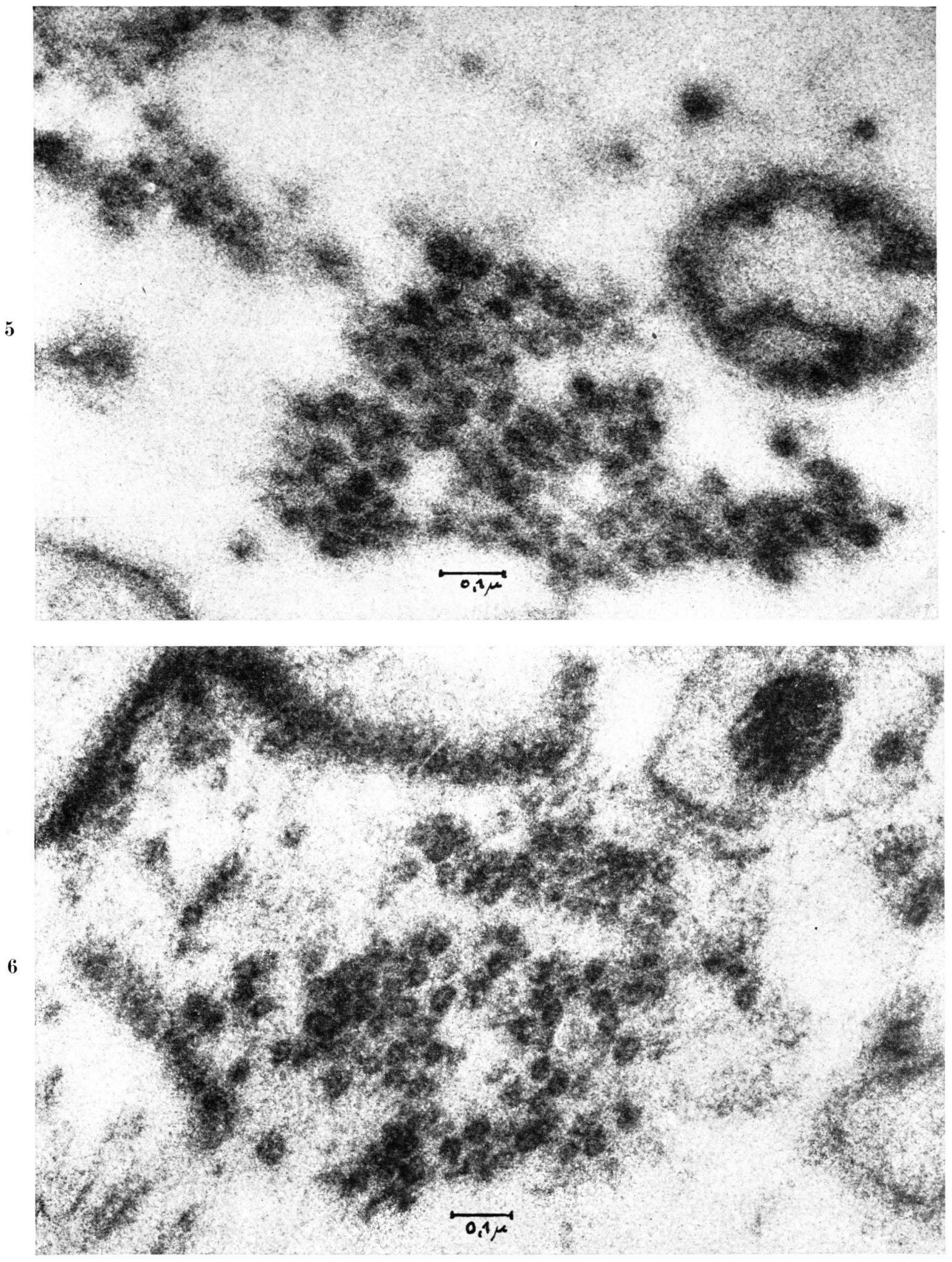

Abb. 5 und 6. Schnitte aus dem Ammonshorn von Kaninchen a und b. Fixierung mit $\mathrm{KMnO}_{4}$. Vergrößerung 100000 -fach. 
$\left(p_{\mathrm{H}}=7,2\right)$ aufgenommen. Die Kontrollkulturen wurden mit virusfreiem Puffer beimpft. Nach einer Adsorptionszeit von $45 \mathrm{Min}$. $\left(37^{\circ} \mathrm{C}\right)$ wurden die Zellen gewaschen, mit CW-Medium überschichtet und dann bei $37{ }^{\circ} \mathrm{C}$ weiter bebrütet.

Der für die fluoreszenzoptischen Untersuchungen benutzte Antikörper wurde von Ratten gewonnen, die eine ME-Infektion überstanden hatten. Das Verfahren entsprach im übrigen dem von Breitenfeld und $\mathrm{S}_{\text {CHÄ- }}$ ${ }_{F E R}{ }^{6}$ beschriebenen. Für die autoradiographischen Studien wurde Tritium markiertes Uridin verwendet, das in erster Linie in RNS eingebaut wird. Den Zellen wurde zu verschiedenen Zeiten p.i. 5 Min. lang ${ }^{3} \mathrm{H}$ Uridin-haltiges Gewebekulturmedium $(18 \mu \mathrm{C} / \mathrm{ml}$, spez. Akt. 1,29 C/mMol) angeboten. Danach wurden sie in Pufferlösung gewaschen, in Alkohol/Eisessig (6:1) fixiert und schließlich mit Kodak AR 10 „stripping film" überzogen.

\section{Ergebnisse}

In den nicht infizierten Kontrollen wurde immer eine intensive radioaktive Markierung im Kern gefunden; die Nucleoli zeigten gegenüber dem Restkern im allgemeinen einen stärkeren Einbau. Das Cytoplasma war praktisch frei von autoradiographisch erfaßbarem Tritium (Abb. $1^{*}$ ).

Ein völlig anderes Bild lieferten ME-infizierte Zellen (Abb. 2). Der Einbau im Kern wurde von der zweiten Stde. p.i. ab gehemmt, dafür trat im Cytoplasma eine starke Markierung auf, die in Kernnähe intensiver war als in den peripheren Teilen der Zelle. Das Uridin muß in RNS eingebaut worden sein, weil die entsprechende Markierung nicht durch Trichloressigsäure (5-proz., $0{ }^{\circ} \mathrm{C}, 5 \mathrm{Min}$.) und Perchlorsäure (10-proz., $0{ }^{\circ} \mathrm{C}, 5 \mathrm{Min}$.), wohl aber nach Vorbehandeln mit Ribonuclease $(0,4 \mathrm{mg}$ pro ml, 2 Stdn., $p_{\mathrm{H}} 6,9,37{ }^{\circ} \mathrm{C}$ ) ausgewaschen werden konnte (Abb. 3). Aller Wahrscheinlichkeit nach wurde diese RNS auch im Cytoplasma produziert. Wenn sie im Kern synthetisiert und anschließend in das Cytoplasma verlagert worden wäre, sollte man bei der angewendeten Versuchstechnik eine stärkere Markierung im Kern erwarten.

Der zeitliche Verlauf der Veränderungen der RNS-Synthese in der infizierten Zellpopulation geht aus Abb. 4 hervor. Danach waren bereits 3 Stdn. p. i. kaum noch Zellen vorhanden, in denen ein Einbau von ${ }^{3} \mathrm{H}$-Uridin im Kern festzustellen war. Von 3 Stdn. p.i. ab nahm aber die Anzahl der Zellen mit RNS-Synthese im Cytoplasma fortlaufend zu.

6 P. M. Breitenfeld u. W. Schäfer, Virology 4, 328 [1957].

* Abb. 1, 2, 3 u. 5 s. Tafel S. 194 b.
Nach den geschilderten Beobachtungen laufen im RNS-Stoffwechsel der infizierten Zellen zumindest zwei, zeitlich und örtlich voneinander getrennte Prozesse ab, nämlich zuerst eine Hemmung der Bildung von RNS im Kern und darauf das Auftreten einer neuen, starken RNS-Synthese im Cytoplasma.

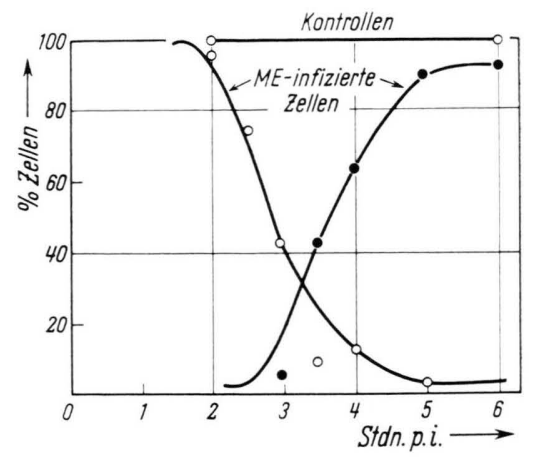

Abb. 4. Syntheseorte der RNS innerhalb einer ME-infizierten L-Zell-Population während des Infektionszyklus. Zum Vergleich dazu die Kontrollen eingetragen: $0=\%$ der Zellen mit Kernmarkierung, $\bullet=\%$ der Zellen mit cytoplasmatischer Markierung.

$\mathrm{Zu}$ ungefähr derselben Zeit, zu der die Synthese von RNS im Cytoplasma beginnt, läßt sich hier erstmals mit Hilfe von fluoreszierendem Antikörper virusspezifisches Antigen nachweisen ( $3^{1 / 2}$ Stdn. p.i.) (Abb. 5). Im Zellkern war über die gesamte Versuchsdauer von 6 Stdn. niemals Virusantigen festzustellen (vgl. l. c. ${ }^{2}$ ). Die Möglichkeit, daß auch im Kern ein Virusprotein gebildet wird, kann dadurch jedoch nicht völlig ausgeschlossen werden. Es könnte sein, daß dieses entweder noch keine antigen wirksame Struktur besitzt oder durch den verwendeten Antikörper nicht erfaßt wurde.

\section{Besprechung der Ergebnisse}

Ähnlich wie bei ME-infizierten Zellen wurde auch nach der Infektion von Krebs-2-Ascites-Tumorzellen mit Enzephalomyocarditis-Virus, das dem ME-Virus verwandt ist, nach Untersuchungen mit ${ }^{14} \mathrm{C}$-Orotsäure eine Hemmung der RNS-Synthese in den Zellkernen festgestellt; darauf finden die Autoren ${ }^{7}$ eine erhöhte Einbaurate von ${ }^{14} \mathrm{C}$-Orotsäure in die RNS der Mitochondrien- und Mikrosomen-Fraktion.

7 E. M. Martin, Progr. Biophys. Biophys. Chem. 11, 253 [1961]. 
Bindende Aussagen über Art und Bedeutung der nach unseren Befunden im Cytoplasma der infizierten Zellen synthetisierten RNS können beim gegenwärtigen Stand der Untersuchungen noch nicht gemacht werden. Die naheliegende Annahme, daß es sich bei der cytoplasmatischen RNS um die RNS der neu gebildeten Viruspartikel handelt, widerspricht den bisherigen Erfahrungen; danach erfolgt bei RNS-haltigen Viren z. B. beim Virus der klassischen Geflügelpest ${ }^{6,8}$ und beim Mäuse-Enzephalomyocarditis-Virus ${ }^{7,9}$ die Synthese der Virus-RNS im Zellkern. Außerdem scheint die Menge der im Cytoplasma synthetisierten RNS, soweit man sie aus der Stärke der Markierung abschätzen kann, größer zu sein, als die der zu erwar-

${ }^{8}$ Ch. Scholtissek u. R. Rott, Z. Naturforschg. 16 b, 109 [1960]. tenden Virus-RNS ${ }^{3}$. Da jedoch die neugebildete RNS und das Virusantigen etwa zur gleichen Zeit und am gleichen Ort innerhalb der Zelle auftreten, liegt die Vermutung nahe, daß die nachgewiesene cytoplasmatische RNS in irgendeiner Form an der Bildung des Virusproteins beteiligt ist. Weitere Untersuchungen zu ihrer Charakterisierung und zur Aufklärung ihrer Funktion sind im Gange.

Den Herren Professoren Dr. W. Beermann und Dr. W. SCHÄFER bin ich für Anregung und freundliche Unterstützung während der Arbeit zu großem Dank verpflichtet.

Die Arbeit wurde mit Mitteln der Deutschen Forschungsgemeinschaft und des Bun desministeriums für Atomkernenergie und Wasserwirts chaf t durchgeführt.

\title{
Verhalten der antigenen und sonstigen biologischen Eigenschaften menschen- und tierpathogener Virusarten beim Behandeln mit salpetriger Säure
}

\author{
II. Mitt.: Verhalten von Myxoviren \\ Von Rudolf Rott und Werner Schäfer \\ Aus dem Max-Planck-Institut für Virusforschung, Tübingen \\ (Z. Naturforschg. 17 b, 160-164 [1962]; eingegangen am 5. Oktober 1961)
}

\begin{abstract}
Ebenso wie beim Poliomyelitis-Virus wird auch beim Influenza-Virus durch längere Einwirkung von $\mathrm{HNO}_{2}$ die antigene Struktur zerstört, außerdem leiden hier noch die hämagglutinierende Komponente und die Virus-Neuraminidase Schaden. Trotzdem lassen sich mit Hilfe dieser Inaktivierungsmethode sowohl beim Influenza-Virus wie auch bei einem weiteren Vertreter der Myxogruppe, dem Newcastle-Disease-Virus, brauchbare Vakzinen gewinnen, wenn man unter den eingehaltenen Bedingungen $\mathrm{HNO}_{2}$ beim Influenza-Virus $3 \mathrm{Stdn}$., beim NDV 1 Stde. einwirken läßt.
\end{abstract}

In der ersten Mitteilung wurden Untersuchungen beschrieben, die sich mit dem Verhalten der antigenen und sonstigen biologischen Eigenschaften des Poliomyelitis-Virus nach Behandeln mit $\mathrm{HNO}_{2}$ befaßten ${ }^{1}$. Sie ergaben, daß bei längerdauernder Einwirkung der salpetrigen Säure nicht nur die Infektiosität der Viruspartikel verlorengeht, sondern auch deren antigene Struktur verändert wird. Bei Viruspräparaten, die hinsichtlich der Infektiosität den für

1 H. Restle, W. Hennessen u. W. Schäfer, Z. Naturforschg., im Druck. eine Poliomyelitis-Vakzine vorgeschriebenen Prüfungsbestimmungen entsprachen, waren die Veränderungen der antigenen Beschaffenheit bereits so tiefgreifend, daß solche Präparate nicht mehr in der Lage waren, die Bildung ausreichender Mengen virusneutralisierender Antikörper zu induzieren. Für die Herstellung einer in der Praxis verwendbaren Poliomyelitis-Vakzine kommt deshalb das $\mathrm{HNO}_{2}$ nicht in Frage.

In der vorliegenden Mitteilung werden Prüfungen ähnlicher Art bei zwei Vertretern der Myxogruppe beschrieben. 